\title{
Intranasal Spray of Oxytocin Might Improve Working Memory Performance in Alzheimer, Tracking with Diffusion Tensor Imaging
}

\author{
Darvishi $\mathrm{A}^{1}$, Pourmennati $\mathrm{B}^{1}$, Ghanbari Kordkandi $\mathrm{Z}^{1}$, Gharibzadeh $\mathrm{Sh}^{2}$ and Fatemeh Bakouie ${ }^{2 *}$ \\ ${ }^{1}$ Student Scientific Research Center (SSRC), Tehran University of Medical Sciences, Iran \\ ${ }^{2}$ Institute for Cognitive and Brain Sciences (ICBS), Shahid Beheshti University, Iran
}

Received: 阱: September 26, 2018; Published: October 03, 2018

*Corresponding author: Fatemeh Bakouie, Institute for Cognitive and Brain Sciences (ICBS), Shahid Beheshti University, Iran

\begin{abstract}
Alzheimer's disease, neurodegenerative process, manifests as episodic memory loss and working memory impairment. Oxytocin affects dopamine and GABA releasing- modifier transmitters in working memory in prefrontal cortex, the center of working memory. Diffusion Tensor Imaging (DTI) is an MRI analyze method which can be used for tractography. We suggest that intranasal Oxytocin administration might improve working memory function which can be determined by tractography with DTI in these patients.
\end{abstract}

\section{Short Communication}

Alzheimer's disease (AD) is a neurodegenerative process; manifests as episodic memory loss and working memory impairment [1]. Prefrontal cortex plays a key role in working memory which depends on modulating transmitters, dopamine and gamma-aminobutyric acid (GABA) $[2,3]$. The neurohypophysial hormone, oxytocin acts on lactation, parturition, modulating stress responses, pain perception, learning and different aspects of social behavior. Investigators suggest that oxytocin has potential therapeutic effects on depressive disorders because it induces hippocampal neurogenesis- a process altered in depression [4]. In this regard intranasal oxytocin administration found to be the most effective way to access to the central nervous system [5]. Dopamine concentrations in Alzheimer patients decreased (about $18-27 \%$ ) in temporal and hippocampal cortices [6]. In addition to dopamine, significant reduction in GABA level has been identified in AD [7]. A recent study suggested that administration of single oxytocin dose has improved "executive component" of working memory (component contributing in information maintenance plus manipulation) in schizophrenic patients [8]. One of the oxytocin analogues induces GABAergic transmission [9]. Prefrontal cortex dopamine amounts might multiply upon oxytocinergic stimulation [10]. This can be resulted from pre-existing oxytocin receptor in prefrontal cortex [8]. Diffusion-weighted magnetic resonance imaging (DWI or DW-MRI) is an imaging method that uses the diffusion of water molecules to generate contrast in MR images [11,12]. A special kind of DWI, diffusion tensor imaging
(DTI), has been used extensively to map white matter tractography (a 3D modeling technique used to visually represent neural tracts) in the brain [13]. Structural connectivity can be explored using diffusion tensor imaging (DTI), which noninvasively assesses the integrity of white matter [11]. Based on abovementioned points, we hypothesize that a trial of intranasal spray of oxytocin would help improving working memory, and to evaluate the effect of treatment we suggest using tractography around hippocampus region.

\section{References}

1. Huntley JD, Howard RJ (2010) Working memory in early Alzheimer's disease: a neuropsychological review. Int J Geriatr Psychiatry 25(2): 121-132.

2. D James Surmeier (2007) Dopamine and working memory mechanisms in prefrontal cortex. J Physiol 581(3): 885.

3. Lewis DA, Hashimoto T, Volk DW (2005) cortical inhibitory neurons and schizophrenia. Nat Rev Neurosci 6(4): 312-324.

4. K. Musaelyan, C Anacker, P A Zunszain, C M Pariante (2011) The effects of oxytocin on hippocampal neurogenesis. Proc Physiol Soc 22: 27.

5. Born J, Lange T, Kern W, McGregor GP, Bickel U, et al. (2002) Sniffing neuropeptides: a transnasal approach to the human brain. Nat Neurosci 5(6): 514-516.

6. Reinikainen KJ, Soininen H, Riekkinen PJ (1990) Neurotransmitter changes in Alzheimer's disease: implications to diagnostics and therapy. J Neurosci Res 27(4): 576-586.

7. Solas M, Puerta E, Ramirez MJ (2014) Treatment options in Alzheimer's disease: THE GABA STORY. Curr pharm 21(34): 4960-4971. 
8. Panayiota G Michalopoulou, Averbeck BB, Kalpakidou AK, Evans S, Bobin T, et al. (2015) The effects of a single dose of oxytocin on working memory in schizophrenia. Schizophrenia Research 169(1-3): 62-63.

9. Daniel Huber, Pierre Veinante, Ron Stoop, (2005) Vasopressin and Oxytocin Excite Distinct Neuronal Populations in the Central Amygdala. Science 308(5719): 245-248.

10. Tracey A Baskerville, Alison J Douglas (2010) Dopamine and Oxytocin Interactions Underlying Behaviors: Potential Contributions to Behavioral Disorders. CNS Neurosci Ther 16(3): 92-123.

ISSN: 2574-1241

DOI: 10.26717/BJSTR.2018.09.001818

Fatemeh Bakouie. Biomed J Sci \& Tech Res

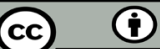

This work is licensed under Creative Commons Attribution 4.0 License

Submission Link: https://biomedres.us/submit-manuscript.php
11. Beaulieu C (2002) The basis of anisotropic water diffusion in the nervous system - a technical review. NMR Biomed 15(7-8): 435-455.

12. Le Bihan D, E Breton (1985) Imagerie de diffusion in-vivo par résonance magnétique nucléaire. C R Acad Sci (Paris) 93(5): 27-34.

13. Filler G Aaron (2010) The History, Development and Impact of Computed Imaging in Neurological Diagnosis and Neurosurgery: CT, MRI, and DTI.

$\begin{array}{ll}\text { BIOMEDICAL } & \text { Assets of Publishing with us } \\ \text { RESEARCHES } & \text { - Global archiving of articles } \\ \text { - Immediate, unrestricted online access } & \text { - Rigorous Peer Review Process } \\ & \text { - Authors Retain Copyrights }\end{array}$

